\title{
Incidence, Risk Factors and Prognosis of Acute Kidney Injury Following Hematopoietic Stem Cell Transplant: A Pilot Study
}

\author{
Amani Anwar Khalil ${ }^{1}$, Laiali T Khalil ${ }^{2}$, Abdalla Awidi ${ }^{3}$ \\ ${ }^{1}$ Department of Clinical Nursing, The University of Fordan, ${ }^{2}$ Department of Nursing, Fordan University Hospital, \\ ${ }^{3}$ Faculty of Medicine and Cell Therapy Center, Fordan University Hospital, Amman, Fordan
}

Background and Objectives: The burden of acute kidney injury (AKI) has not been explored in Jordanian patients who receive hematopoietic stem cell transplant (HSCT). The aim of this study was to evaluate the frequency, risk factors, and mortality of AKI among patients who underwent HSCT.

Methods: A retrospective pilot study included 70 adult patients who received peripheral HSCT was conducted. Weekly measurement of serum creatinine (SCr) was obtained for 3 months after chemotherapy and HSCT. Then, stages of Risk, Injury, and Failure of Kidney were determined based on the Kidney Disease for Improving Global Outcomes (KDIGO).

Results: The median follow-up was 41 months. Mortality was reported in 16 patients (23\%). Out of 60 patients that had SCr values, 19 patients (31.6\%) had AKI in 90 days after chemotherapy. Allogeneic HSCT, male donors, high-dose melphalan protocols and values of blood urea nitrogen (BUN) were significantly higher among patients with AKI. Conclusions: Combining many nephrotoxic drugs and dosing adjustments should be considered in uniform protocols. Multidisciplinary care should be utilized to assess early kidney dysfunction that decreases adverse events and improves outcomes.

Keywords: Acute Kidney Injury, HSCT, Incidence, Risk factors, Mortality, Complications, Jordan

\section{Introduction}

Hematopoietic stem cell transplant (HSCT) is designed to reboot the immune system in many hematological advanced malignant and nonmalignant disorders. Two forms are used: the autologous, which uses the patient as a donor

Received: July 24, 2018, Revised: September 21, 2018,

Accepted: December 11, 2018, Published online: February 28, 2019 Correspondence to Abdalla Awidi

Faculty of Medicine and Cell Therapy Center, Jordan University Hospital, Amman 11962, Jordan

Tel: +962-6-5355000/Ext 23960, Fax: +962-6-5300831

E-mail: abdalla.awidi@gmail.com

(c) This is an open-access article distributed under the terms of the Creative Commons Attribution Non-Commercial License (http://creativecommons.org/ licenses/by-nc/4.0/), which permits unrestricted non-commercial use, distribution, and reproduction in any medium, provided the original work is properly cited.

Copyright (c) 2019 by the Korean Society for Stem Cell Research and the allogeneic, which utilizes another compatible individual as the donor (1). The donated stem cells are derived either from the bone marrow (central HSCT) or from the blood (peripheral HSCT). These methods should be preceded and supported by the administration of chemo-radiotherapy to deplete much of the immune system, suppress the host immune system and prevent graft rejection $(2,3)$. In addition, the administration of antibiotics and immunosuppressive therapy is performed after HSCT to prevent graft vs. host disease (GVHD). In Jordan, descriptive studies and case reports of HSCT in the pediatric population with immunodeficiency disease and malignancies have been conducted. However, more emphasis on HSCT-related morbidity and mortality in adults is warranted $(4,5)$.

In general, patients should be hospitalized and monitored for more than 10 days prior to the procedure (3). Therefore, multidisciplinary care should be directed to- 
ward orientation and teaching of the patient and family for early identification of fever, infection, neutropenia, emotional, cognitive and spiritual needs $(6,7)$. The related-HSCT medication has a toxic effect and produces early and late complications such as acute kidney injury (AKI) despite the type of HSCT. AKI is one of the early medical conditions that could be caused by hemodynamic instability, toxicities of the administered medications and/or conditioning therapy before and after HSCT (5). Adjustment of the chemotherapy dose, reliable facility services and highly trained personnel have begun to show promising indicators of safety in HSCT therapy (8). Yet, the incidence of AKI varied widely between reported studies because of various definitions and assessment methodology among patients with peripheral and central HSCT. Findings indicated a high degree of association between AKI and short and long-term mortality (9-11). However, incidence and risk factors were not adequately revealed in adult Jordanians who received peripheral HSCT.

The Kidney Disease for Improving Global Outcomes (KDIGO) introduced the RIFLE classification as a sensitive and specific assessment in diagnosing AKI among hospitalized and critically ill patients $(12,13)$. However, this classification was not applied prospectively to adult patients who underwent HSCT therapy. The vast majority of studies evaluated AKI in pediatric patients who received the HSCT procedure $(13,14)$. RIFLE was developed to classify acute renal failure (ARF) defined in three grades of severity-Risk (R), Injury (I) and Failure (F). Although a few studies applied this scoring system in patients receiving HSCT, its usefulness in assessing and evaluating outcomes of AKI have shown promising results (11). The objectives of the present study were 1) to determine the current incidence of post HSCT AKI based on the RIFLE criteria, and 2) to identify AKI risk factors and predict long term complications (e.g. relapse) and death associated with post-HSCT AKI in the HSCT Jordanian center within the University of Jordan Hospital.

\section{Materials and Methods}

A retrospective pilot study was conducted between July 2002 and April 2016 on 140 patients at the HSCT Research Center of the University of Jordan Hospital in Amman, Jordan. Only 70 adult patients were included in the study; children and adolescents were excluded, as well as adult patients with missing data. An informed consent to retrieve and review their data for both clinical and research purposes was obtained from the patients on admission. The inclusion criteria were as follows: age $>18$ years and recipient of allo and/or autogeneic transplantation. Data related to patients with hematologic and non-hematologic malignancies that underwent HSCT after a conditioning regimen were obtained for evaluation of frequency and outcome of AKI and its complications. Acute kidney injury was evaluated in patients with allogeneic and autologous HSCT. Grafts were collected from peripheral blood.

\section{Peripheral HSCT protocol}

All patients were hospitalized for peripheral HSCT. Chemotherapy-conditioning protocols were categorized into groups. The first group received cyclophosphamide $50 \sim$ $60 \mathrm{mg} / \mathrm{kg}$ D1 $\sim \mathrm{D} 2+$ fludarabine $30 \sim 35 \mathrm{mg} / \mathrm{m}^{2} \mathrm{D} 1 \sim \mathrm{D} 3 \pm$ ATG $3 \mathrm{mg} / \mathrm{kg}$ D1 $\sim \mathrm{D} 3$. The second group received melphalan $180 \mathrm{mg} / \mathrm{m}^{2} \mathrm{D} 1$. The third group received melphalan $80 \sim 130 \mathrm{mg} / \mathrm{m}^{2} \mathrm{D} 1+$ fludarabine $30 \sim 35 \mathrm{mg} / \mathrm{m}^{2} \mathrm{D} 1 \sim$ D3. The fourth group received melphalan $180 \mathrm{mg} / \mathrm{m}^{2}$ D1+VP-16 700 1200 mg over 2 days OR fludarabine 90 $150 \mathrm{mg}$ over 3 days. The fifth group consisted of others (miscellaneous) (Table 1). No patients in the study received radiation therapy. Broad-spectrum antibiotic prophylaxis was used for neutropenia. Antibiotics included vancomycin, gentamycin, acyclovir, colomycin, amikacin, azithromycin, tienam, amphotericin b, targocid, tazocin and cephalosporins.

\section{Risk factors for acute kidney injury}

Patient characteristics at baseline were collected from medical records including age, gender, HSCT type, primary medical diagnosis, body surface area (BSA), body mass index (BMI), gender of the donor in case of allogeneic HSCT, chemotherapy-conditioning protocols, dose of chemotherapy, major complications and the use of nephrotoxic medications. Renal function was followed for 100 days including serum creatinine ( $\mathrm{SCr}$ ) and blood urea nitrogen (BUN).

Renal function was assessed by $\mathrm{SCr}$ and mean values of SCr were computed at established time intervals: first, second, and third month after chemotherapy. Estimated glomerular filtration rate (eGFR) was calculated by the Modification of Diet in Renal Disease Study equation: eGFR $\left(\mathrm{ml} / \mathrm{min} / 1.73 \mathrm{~m}^{2}\right)=186^{*}$ serum creatinine ${ }^{-1.154}$ *Age ${ }^{-0.203} *(0.742$ if female)* (1.212 if African American). The last part of the equation regarding African American did not apply to the Jordanian population. None of the patients were on maintenance dialysis or had received a renal transplant. RIFLE criteria were used to evaluate the severity of AKI. The RIFLE class was determined based on the worst $\mathrm{SCr}$ value in a 3-month follow-up period. The 
Table 1. Patients characteristics $(n=70)$

\begin{tabular}{|c|c|c|c|c|c|c|}
\hline Variables & Number & $(\%)$ & Mean \pm SD & Median & Min & Max \\
\hline Age $(n=70)$ & & & $32.3 \pm 11$ & 33 & 18 & 62 \\
\hline \multicolumn{7}{|l|}{ Gender $(n=70)$} \\
\hline Male & 43 & $61.4 \%$ & & & & \\
\hline Female & 27 & $38.6 \%$ & & & & \\
\hline \multicolumn{7}{|l|}{ Medical diagnosis $(n=69)$} \\
\hline Nonmalignant & 19 & $28 \%$ & & & & \\
\hline Malignant & 50 & $72 \%$ & & & & \\
\hline \multicolumn{7}{|l|}{ HSCT type $(n=70)$} \\
\hline Auto & 27 & $38.6 \%$ & & & & \\
\hline Allo & 43 & $61.4 \%$ & & & & \\
\hline \multicolumn{7}{|l|}{ Donor gender $(n=44)$} \\
\hline Male & 34 & $77 \%$ & & & & \\
\hline Female & 10 & $23 \%$ & & & & \\
\hline \multicolumn{7}{|l|}{ Event-free survival $(n=41)$} \\
\hline No event recorded & 19 & $46 \%$ & & & & \\
\hline With event of complication & 22 & $54 \%$ & & & & \\
\hline \multicolumn{7}{|l|}{ Death $(n=49)$} \\
\hline No & 33 & $67 \%$ & & & & \\
\hline Yes & 16 & $33 \%$ & & & & \\
\hline \multicolumn{7}{|l|}{ AKI based on RIFLE criteria $(n=60)$} \\
\hline No AKI & 41 & $68.3 \%$ & & & & \\
\hline Risk & 8 & $13.3 \%$ & & & & \\
\hline Injury & 9 & $15 \%$ & & & & \\
\hline Failure & 2 & $3.3 \%$ & & & & \\
\hline Body mass Index (BMI) $(n=64)$ & & & $25.8 \pm 5.4$ & 25.7 & 17.4 & 45.8 \\
\hline Body Surface area $\left(B S A m^{2}\right)(n=64)$ & & & $1.77 \pm 0.9$ & 1.72 & 1.4 & 2.0 \\
\hline Blood urea nitrogen $(\mathrm{BUN})$ & & & $34.9 \pm 27$ & 27.2 & 7.5 & 170 \\
\hline \multicolumn{7}{|l|}{ Conditioning therapy } \\
\hline $\begin{array}{l}\text { Cyclophosphamide } 50-60 \mathrm{mg} / \mathrm{kg}+\text { Fludarabine } \\
30 \sim 35 \mathrm{mg} / \mathrm{m}^{2} \pm \text { ATG } 3 \mathrm{mg} / \mathrm{kg}\end{array}$ & 6 & $8.6 \%$ & & & & \\
\hline Melphalan $180 \mathrm{mg} / \mathrm{m}^{2}$ & 29 & $41.4 \%$ & & & & \\
\hline Melphalan $80 \sim 130 \mathrm{mg} / \mathrm{m}^{2}+$ Fludarabine $30 \sim 35 \mathrm{mg} / \mathrm{m}^{2}$ & 11 & $15.7 \%$ & & & & \\
\hline $\begin{array}{l}\text { Melphalan } 180 \mathrm{mg} / \mathrm{m}^{2}+\mathrm{VP}-16700 \sim 1200 \mathrm{mg} \text { OR } \\
\text { Fludarabine } 90 \sim 150 \mathrm{mg}\end{array}$ & 15 & $21.4 \%$ & & & & \\
\hline Other (miscellaneous & 9 & $12.9 \%$ & & & & \\
\hline
\end{tabular}

change in serum creatinine level was used to classify patients according to the RIFLE criteria. The maximum RIFLE class (risk, injury or failure) of the first 3 months post transplant was considered. The RIFLE criteria include the following four stages: grade 0 , no AKI; risk for AKI that corresponded to an $\mathrm{SCr} \times 1.5$ from baseline; injury that corresponded to an increased $\mathrm{SCr} \times 2$ from baseline; and failure, that corresponded to an increase $\times 3$ from baseline. Baseline measurement of $\mathrm{SCr}$ was assessed at the day of chemotherapy. The urine volume criterion was not applied, as it was missing from patients' records.

\section{Impact of AKI stages on prognosis}

Mortality and complications data were collected from the files of the patients during hospitalization or after dis- charge during follow-up visits. These complications or events included relapse, graft failure, meningitis, acute GVHD, CNS involvement, hemolysis and primary disease progression.

\section{Analysis}

Data were presented as mean \pm standard deviation and frequencies based on variable levels. Comparisons of frequencies between groups were performed using the chisquare test or Fisher's exact test for categorical variables. Median values were compared using the Mann- Whitney U-test. Complications or events were noted at any time following HSCT therapy. Overall survival curves, progression-free survival, and AKI were estimated by the Kaplan-Meier method and compared with the log-rank 
Table 2. Patients characteristics by RIFLE classifications of AKI $(n=70)$

\begin{tabular}{|c|c|c|c|c|c|}
\hline Variables & $\begin{array}{l}\text { No AKI }(\mathrm{n}=41) \\
\text { Median } \pm \text { SD } \\
\text { or } \mathrm{n}(\%)\end{array}$ & $\begin{array}{c}\text { Risk }(\mathrm{n}=8) \\
\text { Median } \pm \mathrm{SD} \\
\text { or } \mathrm{n}(\%)\end{array}$ & $\begin{array}{l}\text { Injury }(n=9) \\
\text { Median } \pm \text { SD } \\
\text { or } n(\%)\end{array}$ & $\begin{array}{l}\text { Failure }(n=2) \\
\text { Median } \pm S D \\
\text { or } n(\%)\end{array}$ & $\mathrm{p}$ value \\
\hline Age $(n=70)$ & $35 \pm 12.2$ & $27 \pm 9.4$ & $33 \pm 7.6$ & $21 \pm 1.4$ & NS \\
\hline \multicolumn{6}{|l|}{ Gender } \\
\hline Male $(n=36)$ & $25(61 \%)$ & $4(50 \%)$ & $6(66.7 \%)$ & $1(50 \%)$ & \multirow[t]{2}{*}{ NS } \\
\hline Female $(n=24)$ & $16(39 \%)$ & $4(50 \%)$ & $3(33.3 \%)$ & $1(50 \%)$ & \\
\hline \multicolumn{6}{|l|}{ Chemotherapy } \\
\hline $\begin{array}{l}\text { Cyclophosphamide } 50 \sim 60 \mathrm{mg} / \mathrm{kg}+\text { Fludarabine } \\
30 \sim 35 \mathrm{mg} / \mathrm{m}^{2} \pm \text { ATG } 3 \mathrm{mg} / \mathrm{kg}\end{array}$ & $3(7.3 \%)$ & $1(12.5 \%)$ & 0 & $1(50 \%)$ & \multirow[t]{5}{*}{0.02} \\
\hline Melphalan $180 \mathrm{mg} / \mathrm{m}^{2}$ & $25(61 \%)$ & $1(12.5 \%)$ & $2(22.2 \%)$ & 0 & \\
\hline $\begin{array}{l}\text { Melphalan } 80 \sim 130 \mathrm{mg} / \mathrm{m}^{2}+\text { Fludarabine } \\
30 \sim 35 \mathrm{mg} / \mathrm{m}^{2}\end{array}$ & $5(12.2 \%)$ & $4(50 \%)$ & $1(11.1 \%)$ & 0 & \\
\hline $\begin{array}{l}\text { Melphalan } 180 \mathrm{mg} / \mathrm{m}^{2}+\mathrm{VP}-16700 \sim 1200 \mathrm{mg} \\
\text { OR Fludarabine } 90 \sim 150 \mathrm{mg}\end{array}$ & $7(17.1 \%)$ & $2(25 \%)$ & $5(55.6 \%)$ & $1(50 \%)$ & \\
\hline Other (miscellaneous & $1(2.4 \%)$ & 0 & $1(11.1 \%)$ & 0 & \\
\hline \multicolumn{6}{|l|}{ HSCT type $(n=60)$} \\
\hline Auto & $22(53.7 \%)$ & 0 & 0 & $1(50 \%)$ & \multirow[t]{2}{*}{$<0.001$} \\
\hline Allo & $19(46.3 \%)$ & $8(100 \%)$ & $9(100 \%)$ & $1(50 \%)$ & \\
\hline BMI & $25.7 \pm 4.5$ & $27 \pm 8.3$ & $24 \pm 5.5$ & $30.5 \pm 10.6$ & NS \\
\hline BSA & $1.8 \pm 0.18$ & $1.7 \pm 0.2$ & $1.7 \pm 0.2$ & $1.8 \pm 0.19$ & NS \\
\hline \multicolumn{6}{|l|}{ Donor gender $($ Allo $=44)$} \\
\hline Male & $16(39 \%)$ & $6(75 \%)$ & $9(100 \%)$ & $1(50 \%)$ & \multirow[t]{2}{*}{0.01} \\
\hline Female & $5(7.3 \%)$ & $2(25 \%)$ & 0 & $1(50 \%)$ & \\
\hline \multicolumn{6}{|l|}{ Medical diagnosis } \\
\hline Malignancies & $11(26.8 \%)$ & $2(25 \%)$ & $2(22.2 \%)$ & $1(50 \%)$ & \multirow[t]{2}{*}{ NS } \\
\hline Non-malignancies & $30(73.2 \%)$ & $6(75 \%)$ & $7(77.8 \%)$ & $1(50 \%)$ & \\
\hline \multicolumn{6}{|l|}{ Nephrotoxic drugs } \\
\hline Nephrotoxic drugs & $32(78 \%)$ & $6(75 \%)$ & $7(77.8 \%)$ & $2(100 \%)$ & \multirow[t]{3}{*}{ NS } \\
\hline No nephrotoxic drugs & $7(18 \%)$ & $2(14.3 \%)$ & $1(11.1 \%)$ & 0 & \\
\hline Unknown cases & $2(4.9 \%)$ & 0 & $1(11.1 \%)$ & 0 & \\
\hline Blood urea nitrogen & $25.5 \pm 11.7$ & $32 \pm 15.9$ & $41.4 \pm 3.5$ & $127.8 \pm 60$ & 0.000 \\
\hline \multicolumn{6}{|l|}{ Survival rate } \\
\hline Survived & $23(77 \%)$ & $4(67 \%)$ & $3(38 \%)$ & 0 & \multirow[t]{2}{*}{0.09} \\
\hline Deceased & 7 (23.3\%) & $2(33.3 \%)$ & $5(63 \%)$ & $1(100 \%)$ & \\
\hline
\end{tabular}

test. All tests were two-sided with a $\mathrm{p}$ value of $\mathrm{p}=0.05$ as statistically significant. Analyses were performed using SPSSs version 21 .

\section{Results}

\section{Patient baseline characteristics}

The baseline characteristics of the 70 participants are presented in Table 1. All the participants received peripheral HSCT. A total of 70 patients with a mean of $32.3 \pm 11$ years (range, 18 to 62 years) were followed. They were 43 males and 27 females. Allograft HSCT was performed for 43 (61.4\%), and auto-graft HSCT for 27 (38.6\%) participants. The median follow-up time after HSCT was 41 months (range, $0 \sim 173$ ). The underling hematological disease requiring HSCT were chronic myeloid leukemia $(\mathrm{n}=4)$, multiple myeloma $(\mathrm{n}=7)$, Hodgkin's lymphoma $(\mathrm{n}=8)$, non-Hodgkin's lymphoma $(\mathrm{n}=5)$, acute lymphatic leukemia $(n=8)$, acute myeloid leukemia $(n=14)$, amyloidosis $(n=3)$, myelodysplastic syndrome (MDS) $(n=3)$, aplastic anemia $(n=12)$ and one case was found in each of the following diseases: myelofibrosis, spinocerebellar ataxia, thalassemia major, paroxysmal nocturnal hemoglobinuria, and osteopetrosis. In all, of 48 patients, 22 (68.6\%) developed an event or complication in less than 24 months after HSCT. Twelve (17.1\%) relapses occurred at median day 256 (IQR 131 315, range 64 4611) after HSCT; 5 (7.1\%) cases developed acute GVHD, which occurred at median day 27 (IQR 23.5 36.5, range 23 39), and at least one of the following events occurred in a single individual; graft failure, meningitis, primary disease progression, hemolysis and CNS involvement. 


\section{Frequency of AKI and risk factors}

Based on RIFLE criteria, in the first month, risk (R) for AKI occurred in 7 (10\%) patients, injury (I) was in $2(2.9 \%)$ and kidney failure (F) occurred in one patient. In the second month of follow-up, risk for AKI occurred in $7(10 \%)$ participants, injury (I) of the kidney was noted in $7(10 \%)$ patients and failure occurred in $2(2.9 \%)$ individuals. In the final month, $8(11.4 \%)$ patients were at risk (R) for AKI, 3 (4.3\%) injured (I) and no patients had renal failure $(\mathrm{F})$. For the present study, the patients were considered with kidney dysfunction based on the RIFLE criteria if they were detected at any stage within the three months follow-up (Table 1 and 2). The estimated glomerular filtration rate mean scores at initial chemotherapy day was $145 \pm 67.5$ (range, 45 to 325 ). The mean scores of weekly eGFR of the patients are illustrated in

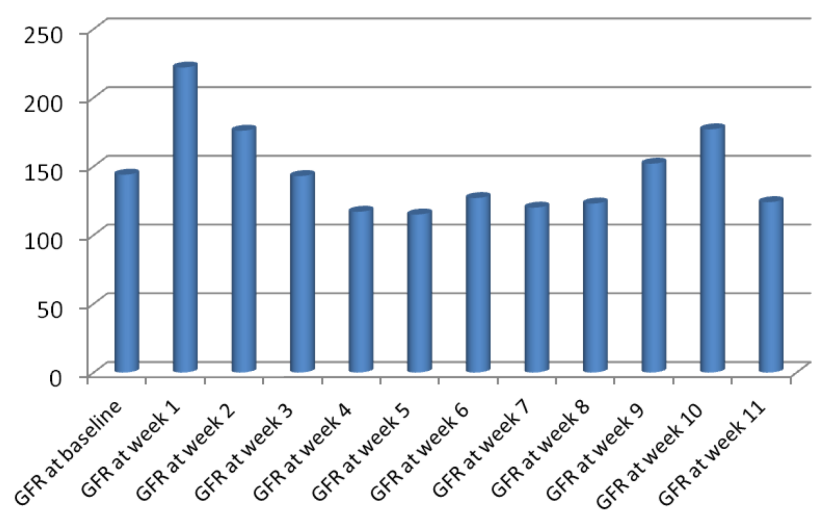

Fig. 1. eGFR in 12 week follow up compared to baseline at chemotherapy day $(n=70)$.

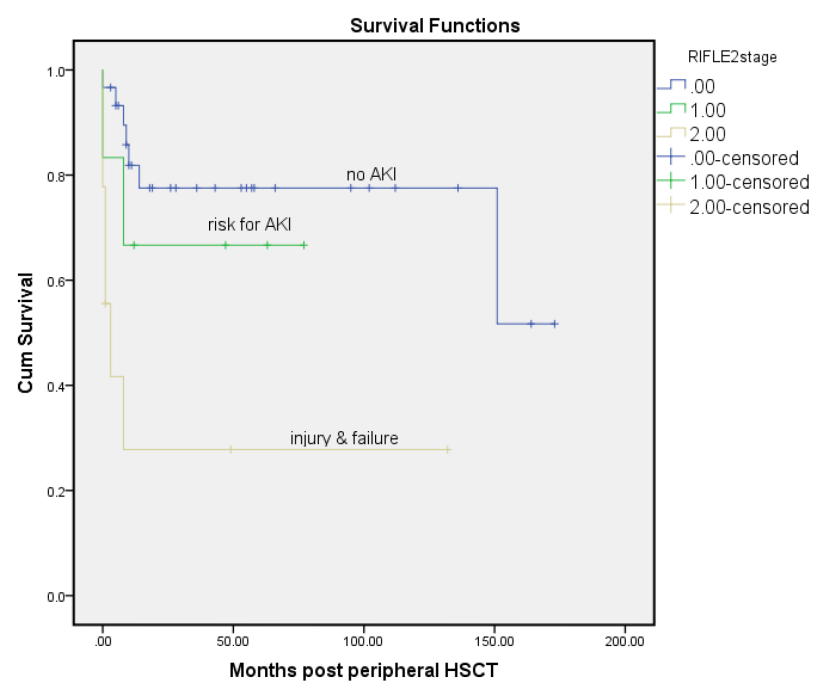

Fig. 2. The Kaplan-Meier curve for death for the different stages of acute kidney injury after peripheral HSCT.
Fig. 1. Risk factors to develop AKI based on RIFLE criteria were chemotherapy protocol type $(p=0.02)$, HSCT type $(p=0.001)$, male gender for donor $(p=0.01)$ and mean value of blood urea nitrogen $(p<0.001)$ (Table 2). Of the 27 patients who received allograft HSCT, 8 were at risk for AKI and 10 patients developed AKI or kidney failure. There was no statistical difference between different stages of AKI in relation to age, gender, underlying primary disease, BMI, BSA or usage of nephrotoxic drugs. Patients were on different chemotherapy protocols based on their diagnosis and stages of the primary disease including, melphalan (melphalan $180 \mathrm{mg} / \mathrm{m}^{2}+\mathrm{VP}-16700 \sim 1200 \mathrm{mg}$ or fludarabine $90 \sim 150 \mathrm{mg}$ ) or higher doses of melphalan (melphalan $180 \mathrm{mg} / \mathrm{m}^{2}$ ) which was associated with higher risk for AKI compared to other protocols (Table 2).

\section{Time to complication and AKI}

Kaplan-Meier survival curve of the three categories of $\mathrm{AKI}$ (no AKI=stage 0, stages of risk and stages of injury to failure were combined) showed a significant difference in a 12-year survival rate, with the best survival in patients with no AKI (stage 0 ) and the worst survival in injury or failure on the RIFLE criteria (log rank test, $\mathrm{p}=0.001$ ). Events or complications happened at an average of 19.3 months in patients with no AKI, and 3.6 months in a risk group and 2 months in patients with injury and failure. It could be speculated that patients with existing AKI based on RIFLE criteria may develop a complication earlier than patients without AKI.

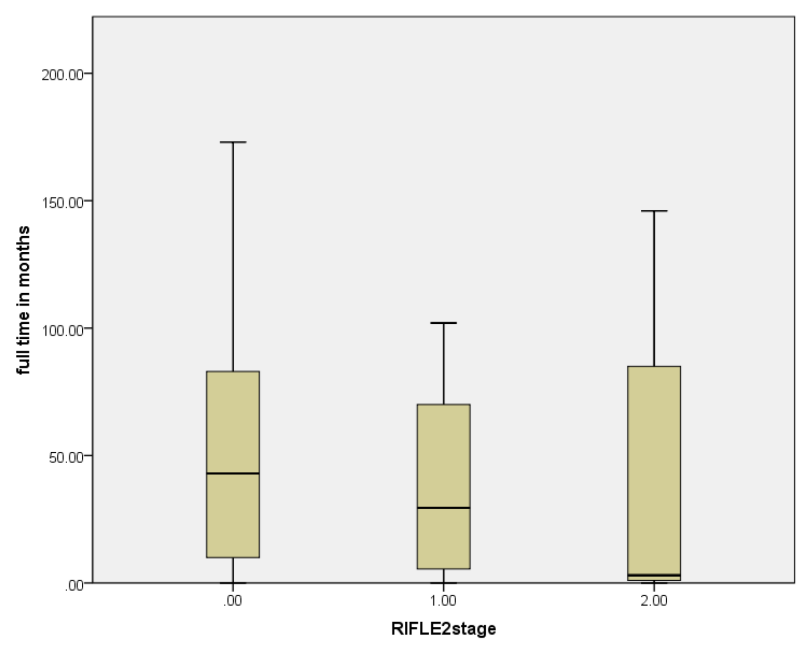

Fig. 3. Survival time of different RIFLE classification after non-myeloablative HSCT. The upper, middle and lower horizontal lines represent the 75th, 50th and 25th percentiles of variable respectively. 


\section{Time to death and AKI}

The Kaplan-Meier survival curve (Fig. 2) of the three categories of AKI (no AKI=stage 0 , stages of risk and stages injury to failure were combined) showed a significant difference in 12 years survival, with the best survival in patients with no AKI (stage 0) and the worse survival in injury or failure on the RIFLE criteria (log rank test, $\mathrm{p}=0.001)$. The deaths happened at an average of 130-months in no AKI patients, and 53-months in the at risk group and 38-months in patients with AKI and kidney failure. Patients with AKI based on RIFLE criteria died earlier than patients with no AKI (Fig. 3).

\section{Discussion}

HSCT is providing a fundamental immunological repair to many individuals with challenging malignant and non-malignant diseases who had no hope with conventional therapies $(1,15)$. Quality of care should be optimized to achieve excellent patient outcomes through holistic care by the multidisciplinary team $(6,7)$. The results of this present study suggest that AKI is an early complication that commonly happens in the first 90 days and may have a negative effect on prognosis. The overall incidence of AKI during the 3-month follow-up was 31.6\%, which is lower than the rates reported in previous research (12, 14). The KDIGO Clinical Practice Guideline for Acute Kidney Injury introduced the RIFLE criteria- Risk, Injury, and Failure; and the two outcome classes: Loss and End-Stage Renal Disease (ESRD) to define AKI and the severity classes (13). Many risk factors played a role in deteriorating renal function in different populations (16), however, patients undergoing the HSCT procedure were rarely investigated. Risk for AKI or failure was significantly correlated with chemotherapy protocol type, HSCT type, donor gender, and blood urea nitrogen. However, BMI and BSA were not different for different stages of kidney dysfunction. Others found that Jordanian patients with ESRD receiving hemodialysis were more likely to have low BMI compared to patients with earlier stages of CKD (16). Nephrologists and oncology nurse specialists should receive special training in screening, diagnosing, managing and treating AKI in this setting.

According to the most recent criteria on the evaluation and severity of $\mathrm{AKI}$, the incidence among the allogeneic HSCT ranged from $20 \%$ to $90 \%$ versus $<20 \%$ as expected for those undergoing autogenic HSCT $(9,10)$. These figures correspond with the incidence of $\mathrm{AKI}$ in the present study. In the first month, the incidence of AKI was $16.6 \%$, $32 \%$ for the second month and $30 \%$ for the 3 rd month.
None of the Jordanian patients had AKI at the time of HSCT, while Shingai and colleagues found an early onset of AKI at the HSCT time which corresponded to $22 \%$ of an allogeneic HSCT Japanese sample and $42.7 \%$ as a late AKI at 100 days after HSCT (12). The longer time to AKI occurrence in the peripheral myeloablative HSCT, the less infectious diseases and organ failure rate happened (11). RIFLE classification was not applied adequately in patients who had undergone HSCT. Biological markers and a test for creatinine clearance should be compared with SCr and urine output as the gold standard markers for kidney function in this population $(17,18)$.

The present study found that high doses of chemotherapy (melphalan) were associated with AKI. Yet, the incidence of AKI was mild; none of the patients required dialysis. Conditioning chemotherapy is a common risk factor for AKI, in addition to the combined effects of antibiotics and immunosuppressive drugs. However, this conclusion remains debatable based on dose adjustment and usage of drug combination $(8,12)$. Moreover, it was difficult to determine the actual effects of these nephrotoxic medications, because many different protocols have been used in many settings (8). It was suggested that uniform guidelines are warranted in HSCT centers that specify alternative conditioning protocols for each disease or condition. Combining many nephrotoxic medications and dosing adjustment should be considered in protocols using cyclosporine and amphoteracin B. Given the nephrotoxic effect of these medications, there was no statistically significant association between AKI and usage of nephrotoxic medications. However, allogeneic HSCT contributed significantly to the occurrence of AKI in comparison to autogeneic HSCT. This indicates indirectly, that nephrotoxic medications such as methotrexate administered to prevent GVHD in allogeneic HSCT clinically, contributed to the development of AKI. Yet, it is worth mentioning that veno-occlusive disease (VOD) of the liver was not within the complication list of the present sample. VOD is a consequence of decreased renal perfusion and $75 \%$ of allogeneic HSCT therapy recipients were found to have VOD within the first month of HSCT (16).

It was clear that the patients' prognosis and outcomes differed based on the severity and timing of AKI. About 5 out of 9 patients (63\%) who developed AKI deceased in the current study. Consistently, Chow et al, (2017) found that patients who underwent HSCT were at a higher risk to develop morbidity such as chronic GVHD, relapse of the original disease and hospitalization compared to non-HSCT patients diagnosed with cancer (18). The HSCT procedure is intended to heal and improve survival 
rates in patients with malignancies and immunological disorders. The present study indicates patients who received allogeneic HSCT and who were on pre-HSCT high dose chemotherapy (melphalan) were more likely to develop AKI. However, the therapeutic dose of chemotherapy in relation to renal dysfunction is inconsistent among studies (8). More prospective studies are needed that use limited chemotherapy protocols with HSCT patients (2).

\section{Conclusions}

In summary, the incidence of AKI is significantly and clinically higher in allogeneic than autologous HSCT (49\% vs. 9\%), However, it is lower than the reported in previous studies. Mortality rates are not increased in autogeneic HCST patients compared to patients' receiving allogeneic HSCT. No patient in the present Jordanian sample had multiple organ dysfunction linked to intense conditioning chemotherapy regimens such as VOD, engraftment syndrome or required dialysis treatment. It is not clear if renal dysfunction is directly associated with poor prognosis or mediated by the effect of conditioning chemotherapy and nephrotoxic drugs. There is a need to develop a survey that follows patients undergoing HSCT procedures in Jordan. The survey is intended to follow current practices and findings for health care providers and stakeholders as updates for better outcomes and prognosis. The RIFLE classification is based on either the SCr or urine output, which is not adequately tested for sensitivity and specificity in patients having HSCT. Therefore, more evidence-based work is needed to assess better biomarkers (cystatin C, interleukin-18) for earlier prediction of possible infections and relapses.

\section{Acknowledgments}

This research did not receive any specific grant from funding agencies in the public, commercial, or not-forprofit sectors.

\section{Potential Conflict of Interest}

The authors declare no conflict of interest.

\section{References}

1. Ljungman $P$, Bregni $M$, Brune $M$, Cornelissen J, de Witte T, Dini G, Einsele H, Gaspar HB, Gratwohl A, Passweg J, Peters C, Rocha V, Saccardi R, Schouten H, Sureda A, Tichelli A, Velardi A, Niederwieser D; European Group for Blood and Marrow Transplantation. Allogeneic and autologous transplantation for haematological diseases, solid tu- mours and immune disorders: current practice in Europe 2009. Bone Marrow Transplant 2010;45:219-234

2. Majhail NS, Farnia SH, Carpenter PA, Champlin RE, Crawford S, Marks DI, Omel JL, Orchard PJ, Palmer J, Saber W, Savani BN, Veys PA, Bredeson CN, Giralt SA, LeMaistre CF. Indications for autologous and allogeneic hematopoietic cell transplantation: guidelines from the American Society for Blood and Marrow Transplantation. Biol Blood Marrow Transplant 2015;21:1863-1869

3. Ljungman $P$, Gratwohl A. Indication and current practice. In: Ljungman P, Gratwohl A, editor. Indications and current practice for allogeneic and autologous HSCT for haematological diseases, solid tumors and immune disorders 2008. Barcelona: European Group for Blood and Marrow Transplantation.

4. Amayiri N, Al-Zaben A, Ghatasheh L, Frangoul H, Hussein AA. Hematopoietic stem cell transplantation for children with primary immunodeficiency diseases: single center experience in Jordan. Pediatr Transplant 2013;17:394-402.

5. Aladily TN, Mohammad RS, Al-Khader A, Awidi AS. Essential thrombocythemia in a two-year-old child, responsive to hydroxyurea but not aspirin. Oman Med J 2017; 32:243-246

6. Alaloul F, Brockopp DY, Andrykowski MA, Hall LA, Al Nusairat TS. Quality of life in Arab Muslim cancer survivors following hematopoietic stem cell transplantation: comparison with matched healthy group. Support Care Cancer 2015;23:2157-2164

7. Alaloul F, Schreiber JA, Al Nusairat TS, Andrykowski MA. Spirituality in Arab Muslim hematopoietic stem cell transplantation survivors: a qualitative approach. Cancer Nurs 2016;39:E39-47

8. Bird JM, Fuge R, Sirohi B, Apperley JF, Hunter A, Snowden J, Mahendra P, Milligan D, Byrne J, Littlewood T, Fegan C, McQuaker G, Pagliuca A, Johnson P, Rahemtulla A, Morris C, Marks DI; British Society of Blood and Marrow Transplantation. The clinical outcome and toxicity of high-dose chemotherapy and autologous stem cell transplantation in patients with myeloma or amyloid and severe renal impairment: a British Society of Blood and Marrow Transplantation study. Br J Haematol 2006;134:385-390

9. Saddadi F, Najafi I, Hakemi MS, Falaknazi K, Attari F, Bahar B. Frequency, risk factors, and outcome of acute kidney injury following bone marrow transplantation at $\mathrm{Dr}$ Shariati Hospital in Tehran. Iran J Kidney Dis 2010;4:2026

10. Liu H, Li YF, Liu BC, Ding JH, Chen BA, Xu WL, Qian J. A multicenter, retrospective study of acute kidney injury in adult patients with nonmyeloablative hematopoietic SCT. Bone Marrow Transplant 2010;45:153-158

11. Lopes JA, Jorge S, Neves M. Acute kidney injury in HCT: an update. Bone Marrow Transplant 2016;51:755-762

12. Shingai N, Morito T, Najima Y, Kobayashi T, Doki N, Kakihana K, Ohashi K, Ando M. Early-onset acute kidney injury is a poor prognostic sign for allogeneic SCT recipients. Bone Marrow Transplant 2015;50:1557-1562 
13. Kidney Disease Improving Global Outcomes (KDIGO) Acute Kidney Injury Work Group. KDIGO Clinical Practice Guideline for Acute Kidney Injury. Kidney Int Suppl 2012;2:1-138

14. Aladily TN, Mohammad RS, Al-Khader A, Awidi AS. Essential thrombocythemia in a two-year-old child, responsive to hydroxyurea but not aspirin. Oman Med J 2017; 32:243-246

15. Passweg JR, Baldomero H, Bader P, Bonini C, Cesaro S, Dreger P, Duarte RF, Dufour C, Kuball J, Farge-Bancel D, Gennery A, Kröger N, Lanza F, Nagler A, Sureda A, Mohty M. Hematopoietic stem cell transplantation in Europe 2014: more than 40000 transplants annually. Bone Marrow Transplant 2016;51:786-792
16. Alramly M, Darawad MW, Khalil AA. Slowing the progression of chronic kidney disease: comparison between predialysis and dialysis in Jordanian patients. Ren Fail 2013;35:1348-1352

17. Parikh CR, McSweeney PA, Korular D, Ecder T, Merouani A, Taylor J, Slat-Vasquez V, Shpall EJ, Jones RB, Bearman SI, Schrier RW. Renal dysfunction in allogeneic hematopoietic cell transplantation. Kidney Int 2002;62:566-573

18. Chow EJ, Cushing-Haugen KL, Cheng GS, Boeckh M, Khera N, Lee SJ, Leisenring WM, Martin PJ, Mueller BA, Schwartz SM, Baker KS. Morbidity and mortality differences between hematopoietic cell transplantation survivors and other cancer survivors. J Clin Oncol 2017;35:306-313 